\title{
The dinoflagellates Durinskia baltica and Kryptoperidinium foliaceum retain functionally overlapping mitochondria from two evolutionarily distinct lineages Behzad Imanian and Patrick J Keeling*
}

\author{
Address: Canadian Institute for Advanced Research, Department of Botany, University of British Columbia, 3529-6270 University Boulevard, \\ Vancouver, British Columbia V6T 1Z4, Canada \\ Email: Behzad Imanian - ashkboos@can.rogers.com; Patrick J Keeling* - pkeeling@interchange.ubc.ca \\ * Corresponding author
}

Published: 24 September 2007

BMC Evolutionary Biology 2007, 7:172 doi:10.1186/147/-2/48-7-172
Received: 30 April 2007

Accepted: 24 September 2007

This article is available from: http://www.biomedcentral.com//47/-2/48/7//72

(c) 2007 Imanian and Keeling; licensee BioMed Central Ltd.

This is an Open Access article distributed under the terms of the Creative Commons Attribution License (http://creativecommons.org/licenses/by/2.0), which permits unrestricted use, distribution, and reproduction in any medium, provided the original work is properly cited.

\begin{abstract}
Abtract
Background: The dinoflagellates Durinskia baltica and Kryptoperidinium foliaceum are distinguished by the presence of a tertiary plastid derived from a diatom endosymbiont. The diatom is fully integrated with the host cell cycle and is so altered in structure as to be difficult to recognize it as a diatom, and yet it retains a number of features normally lost in tertiary and secondary endosymbionts, most notably mitochondria. The dinoflagellate host is also reported to retain mitochondrion-like structures, making these cells unique in retaining two evolutionarily distinct mitochondria. This redundancy raises the question of whether the organelles share any functions in common or have distributed functions between them.

Results: We show that both host and endosymbiont mitochondrial genomes encode genes for electron transport proteins. We have characterized cytochrome c oxidase I (coxl), cytochrome oxidase 2 (cox2), cytochrome oxidase 3 (cox3), cytochrome b (cob), and large subunit of ribosomal RNA (LSUrRNA) of endosymbiont mitochondrial ancestry, and coxI and cob of host mitochondrial ancestry. We show that all genes are transcribed and that those ascribed to the host mitochondrial genome are extensively edited at the RNA level, as expected for a dinoflagellate mitochondrionencoded gene. We also found evidence for extensive recombination in the host mitochondrial genes and that recombination products are also transcribed, as expected for a dinoflagellate.

Conclusion: Durinskia baltica and $K$. foliaceum retain two mitochondria from evolutionarily distinct lineages, and the functions of these organelles are at least partially overlapping, since both express genes for proteins in electron transport.
\end{abstract}

\section{Background}

The endosymbiotic origins of plastids and mitochondria share a number of characteristics in common, $[1,2]$, but differ in the complexity of their evolutionary history following their origin and initial integration. Whereas mitochondria originated once and have apparently never been lost [3-5], plastids have spread between eukaryotic lineages several times in events referred to as secondary and tertiary endosymbioses. Generally these secondary and tertiary endosymbionts have degenerated so far that all that remains is a plastid with extra membranes [6], but in a few exceptional cases intermediate stages of reduction 
are known, and these may provide interesting glimpses into how complexity is lost.

One of the characters that is absent from nearly all known examples of secondary and tertiary endosymbionts is the mitochondrion. This contrasts with the fact that mitochondria have never been lost in any other eukaryotic lineage. Even in the most severely reduced, anaerobic parasites which lack oxidative phosphorylation, highly reduced organelles called mitosomes and hydrogenosomes are found [3-5]. Some of these have no direct role in energy metabolism, but iron-sulfur cluster biosynthesis is a common function $[5,7,8]$. These relict organelles suggest mitochondria are resistant to outright loss, raising questions about why mitochondria appear to be one of the more dispensable features of algae taken up during secondary and tertiary endosymbiosis events.

The single clear exception to this is found in a group of related dinoflagellates that harbour a diatom tertiary endosymbiont. This group contains several species (see [9] for a recent summary), and here we have examined two: Durinskia baltica [10] and Kryptoperidinium foliaceum $[11,12]$. Several of these genera (including Durinskia and Kryptoperidinium) have been shown to share a common pennate diatom endosymbiont, arguing that the endosymbiosis is stable through evolutionary time $[13,14]$. Interestingly, this may not hold for the whole group, since the endosymbiont of Peridinium quinquecorne is a centric diatom [15], suggesting that the integration may have spanned a long period of time and different transient endosymbionts were ultimately fixed in these two subgroups. Nevertheless, the endosymbionts of D. baltica and K. foliaceum are no longer transient in the short term, they have lost motility and cell wall and, although some chromatin condensation occurs during sexual reproduction in D. baltica, typical chromosomes are not found within the endosymbiont nucleus at any stage of its life cycle $[16,17]$. During the endosymbiotic nuclear division, neither a spindle apparatus nor any microtubules have been observed [18], and the amitotic division of this nucleus results in unequal daughter nuclei and significantly larger amount of DNA in the nucleus than that reported in other diatoms [19].

The endosymbiont has clearly been reduced in many ways, but some of its most interesting characteristics are what it has retained. This includes plastids surrounded by endoplasmic reticulum (ER) that is continuous with the outer membrane of the nucleus, a plasma membrane that separates it from the host cytoplasm, a multi-lobed, prominent nucleus with a genome, ribosomes, dictyosomes, and mitochondria $[16,20]$.
It is the retention of mitochondria that makes this endosymbiont stand out, in particular since D. baltica and $K$. foliaceum host cells have also been reported to retain mitochondria. The loss of endosymbiont mitochondria in virtually all known examples of secondary and tertiary endosymbiotic events suggests retaining two mitochondria is either unnecessary or even deleterious. The loss of one of these organelles may be ongoing, but it is also possible that both compartments require mitochondrial function or that they have distributed essential functions between them. We have previously shown [9] that the $K$. foliaceum endosymbiont mitochondrion contains a genome and expresses genes for cytochrome c oxidase subunit $1(\cos 1)$, cytochrome c oxidase subunit $3(\cos 3)$, and cytochrome b (cob). However, no data are available from the host mitochondrion, and with the function of this organelle completely unknown we cannot address the possibility that the two organelles have overlapping or differentiated function.

In order to determine whether this unique mitochondrial redundancy extends to the functional level, we characterized seven mitochondrial genes of $D$. baltica: five from the endosymbiont (cox1, cox2, cox3, cob, and LSUrRNA) and two from the host (cox1 and $c o b$ ), and confirmed that $\operatorname{cox} 2$ and LSUrRNA from the endosymbiont and $\operatorname{cox} 1$ from the host are also present in K. foliaceum. Most significantly, in D. baltica, cox 1 and $c o b$ are present and expressed in both mitochondria, and those in the host are heavily edited, as expected for a functional dinoflagellate mitochondrial gene [21-23]. All available data therefore suggest that both the host and endosymbiont mitochondria are actively expressing genes functional in oxidative phosphorylation and energy production.

\section{Results and discussion Characterization of endosymbiont mitochondrial genes and transcripts}

PCR amplification using diatom-specific primers and total D. baltica DNA (or RNA, see below), resulted in fragments of the expected sizes for five genes: $c o x 1, c o x 3, c o b$, cox2, and LSUrRNA. Sequencing multiple clones yielded a single copy of each gene. Only a short fragment of cox1 could be amplified from DNA, probably due to the presence of long type II introns such as those found in diatoms Phaeodactylum tricornutum and Thalassiosira pseudonana and the endosymbiont of $K$. foliaceum [9], so the remainder was recovered from RNA by RT-PCR. Diatom-derived genes for $c o x 1, c o x 3$ and $c o b$ are already known from $K$. foliaceum [9], so to complement the D. baltica data we also amplified the K. foliaceum cox2 and LSUrRNA.

The phylogenies of all five genes (Fig. 1, 2, 3, 4, 5) generally resembled trees based on nuclear genes, with relatively strong support for the monophyly of alveolates and 


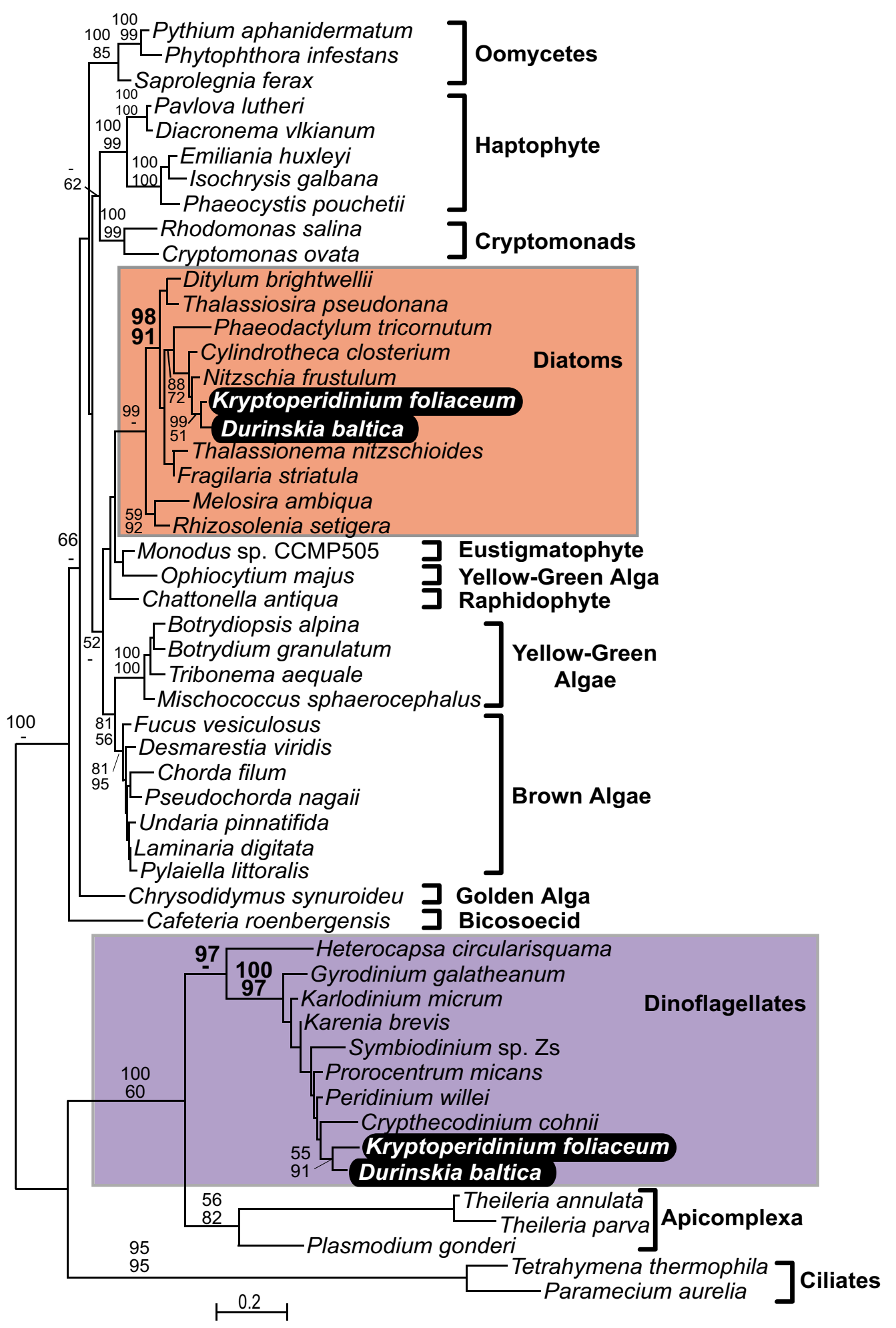

Figure I

Protein maximum likelihood phylogeny of cytochrome c oxidase I (cox I). Numbers at nodes indicate bootstrap support for major nodes over $50 \%$ from ML (top) and distance (bottom). A dash (-) indicates support less than $50 \%$. Major groups are labeled to the right, with diatoms (red) and dinoflagellates (purple) indicated by a box and D. baltica and K. foliaceum genes in black. 


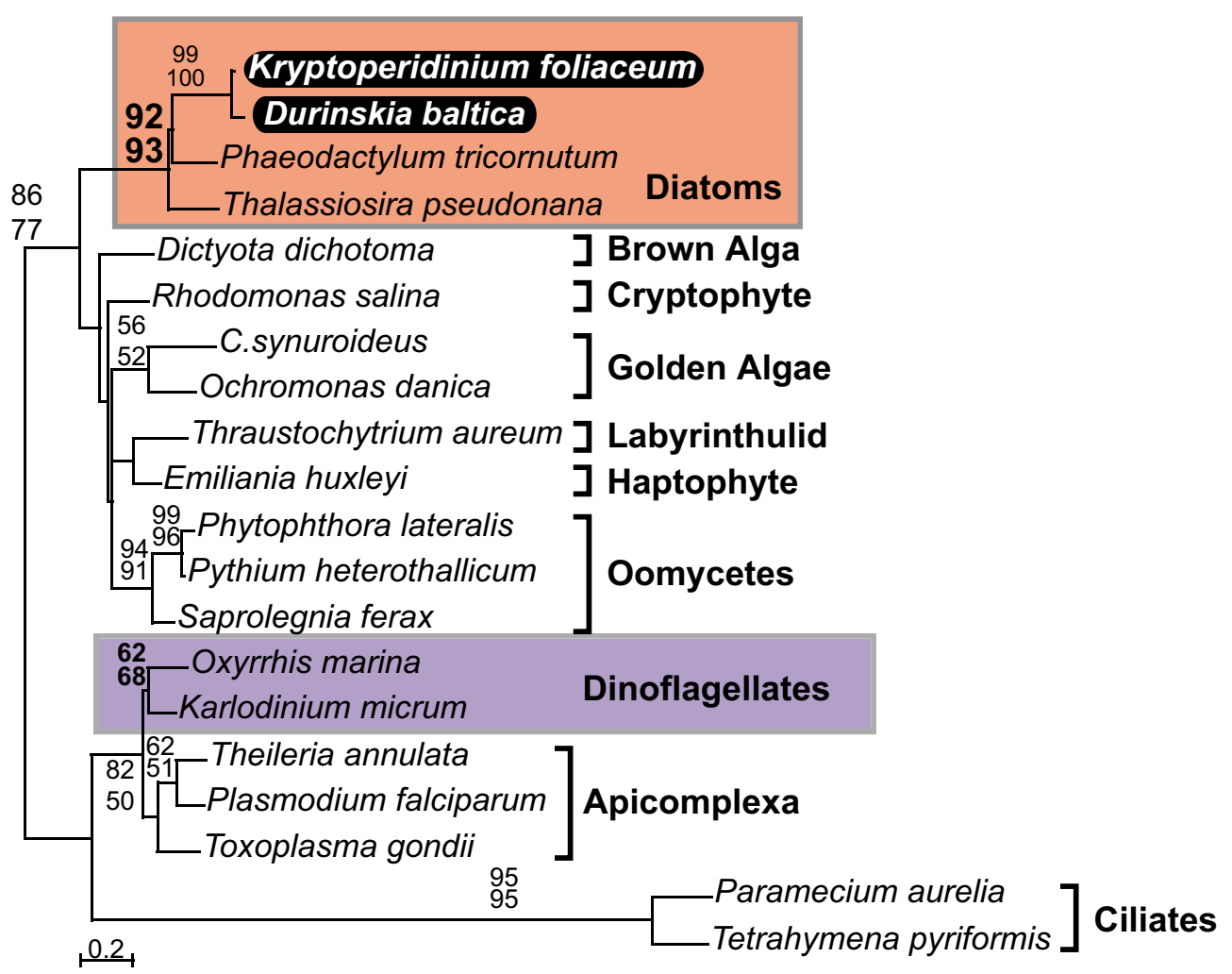

Figure 2

Protein maximum likelihood phylogeny of cytochrome oxidase 2 (cox2). Numbers at nodes indicate bootstrap support for major nodes over $50 \%$ from ML (top) and distance (bottom). A dash (-) indicates support less than $50 \%$. Major groups are labeled to the right, with diatoms (red) and dinoflagellates (purple) indicated by a box and $D$. baltica and $K$. foliaceum genes in black.

sister relationship between dinoflagellates and apicomplexans [24,25]. We also noted that haptophytes and cryptophytes are sister groups with strong support in $c o b$ trees (Fig. 4) and weakly so in $\operatorname{cox} 1$ and $\operatorname{cox} 3$ trees (Fig. 1 and 3), as has been suggested in other analyses [26-29]. Most importantly, however, in all five phylogenies the distinction between the expected positions of host and endosymbiont-derived genes was unambiguous, and in all five trees the $D$. baltica gene amplified with diatom-specific primers branched within the diatom clade with strong support (Fig. 1, 2, 3, 4, 5). Moreover, D. baltica consistently grouped with $K$. foliaceum with strong support (with the exception of distance analysis of $\operatorname{cox} 1$, where the overlap between the two sequences is relatively short). This is in disagreement with the proposal that these dinoflagellates are products of separate endosymbiotic events [30], but consistent with the analyses of nuclear small-subunit rRNA genes from the hosts in these two dinoflagellates [14] and the hypothesis that these two species, and most likely their other close relatives, resulted from a single endosymbiotic event $[13,15,31,32]$. Together, D. baltica and $K$. foliaceum branched specifically with pennate dia- toms (i.e. Nitzschia or Cylindrotheca, Phaodactylum), which is also consistent with evidence that the endosymbiont is a descendent of a pennate diatom $[9,14,33,34]$. Overall, these trees strongly support the conclusion that $\operatorname{cox} 1, \operatorname{cox} 3$, $\operatorname{cob}$, cox2, and LSUrRNA are all present in the mitochondrial genome of the endosymbiont.

To confirm that all five genes are actively expressed, each was also amplified from RNA using RT-PCR. All diatomderived cDNA sequences were identical to their corresponding genes, providing further evidence for these genes being from the endosymbiont mitochondrion, because the mitochondrial transcripts in dinoflagellates are extensively edited $[22,35,36]$.

\section{Characterization of host mitochondrial genes and transcripts}

The presence and expression of cox and cob genes in the endosymbiont mitochondria suggests this organelle is engaged in electron transport. The pressing question is therefore the nature of the host organelle, but no data have been gathered from it for comparison. Dinoflagellate 


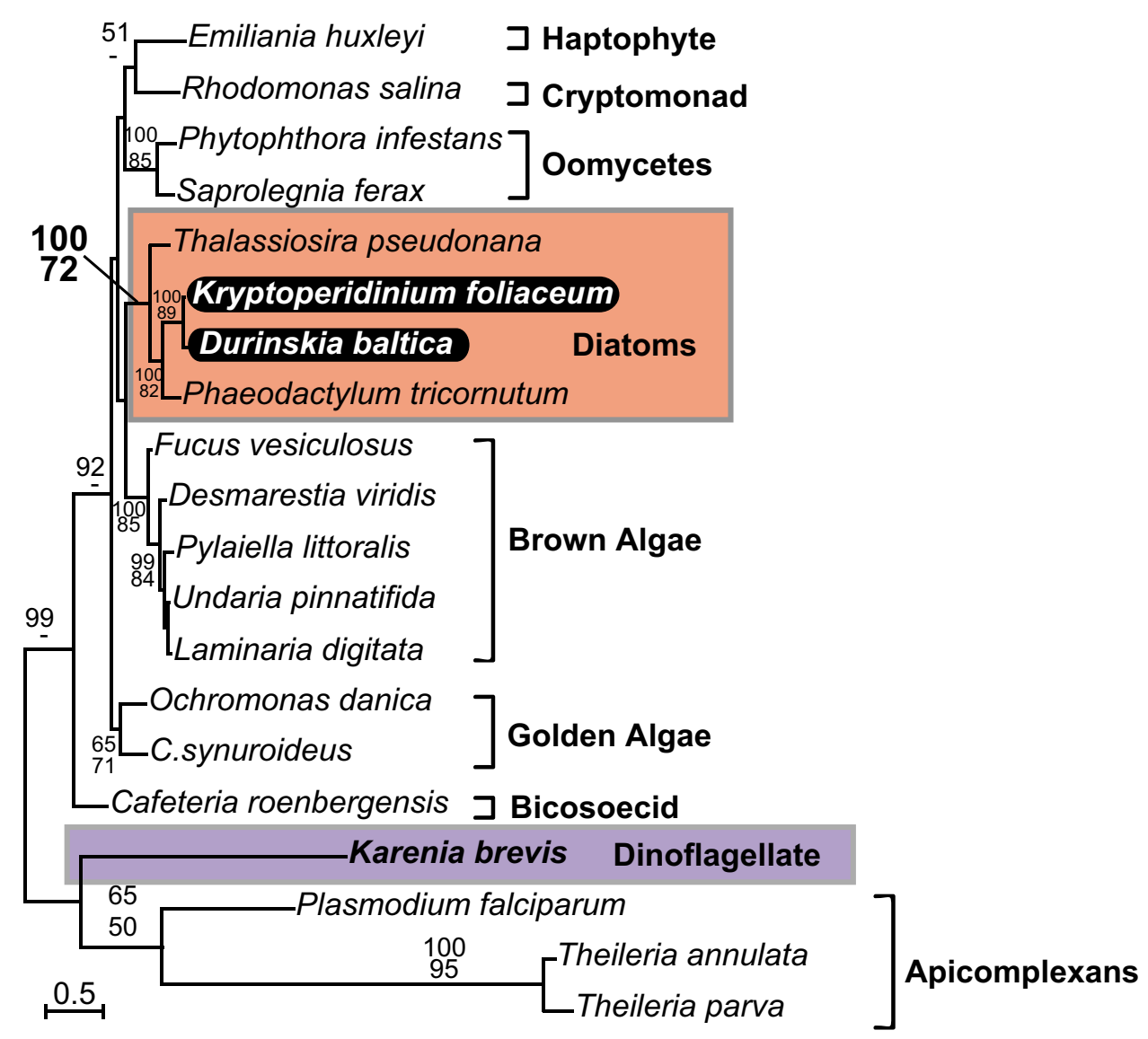

Figure 3

Protein maximum likelihood phylogeny of cytochrome oxidase 3 (cox3). Numbers at nodes indicate bootstrap support for major nodes over $50 \%$ from ML (top) and distance (bottom). A dash (-) indicates support less than $50 \%$. Major groups are labeled to the right, with diatoms (red) and dinoflagellates (purple) indicated by a box and D. baltica and K. foliaceum genes in black.

mitochondrial genomes only encode three protein-coding genes: $\operatorname{cox} 1$, cox3, and $\operatorname{cob}$ [23]. The LSU rRNA has been extensively fragmented and rearranged [37], and cox2 has been split and moved to the nucleus [38], so only cox1, $c o x 3$, and $c o b$ were sought in the mitochondrial genome. We used dinoflagellate-specific primers for all three genes in RT-PCR with total D. baltica RNA, and identified fragments of $\operatorname{cox} 1$ and $c o b$. Using 3' RACE, we also recovered the 3 ' end of the D. baltica cob gene. We also recovered 6 additional copies of cox 1 transcripts (Fig. 6), each of which contained inserts that differed in position, size, and sequences, and disrupted the reading frame. Inserts ranged from 81 to $453 \mathrm{bp}$. Two inserts at slightly different positions of RNA2 and RNA3 were similar in size and sequences, and both of these contained a $151 \mathrm{bp}$ portion of the cob gene flanked by two small (about 20 bp) noncoding fragments (Fig. 6). Another insert contained a 75 bp fragment with over $90 \%$ identity to non-coding fragments from the dinoflagellates Alexandrium catenella
(Genbank accession: AB265207) Gonyaulax polyedra (Genbank accession: AF142472). We did not sequence a DNA clone lacking an insert, but the mitochondrial genome of other dinoflagellates is known to contain many copies of each gene and many rearrangements $[21,23]$, so the intact copy of the gene was most likely simply not sampled. Given the highly fragmented and divergent nature of dinoflagellate mitochondrial rRNAs [37], it is possible this 75 bp represents an as yet unidentified fragment of either the LSU or SSU.

PCR using genomic DNA from $D$. baltica resulted in a single cob gene fragment (12 identical clones were sequenced), and six different cox 1 fragments (seven different clones were sequenced). As with cDNAs, each cox1 gene contained a unique insert (Fig. 6). Most inserts were unique, but many contained small imperfect repeats in common, and the positions of the inserts within cox 1 were variable and inevitably a portion of $\operatorname{cox} 1$ was missing at 


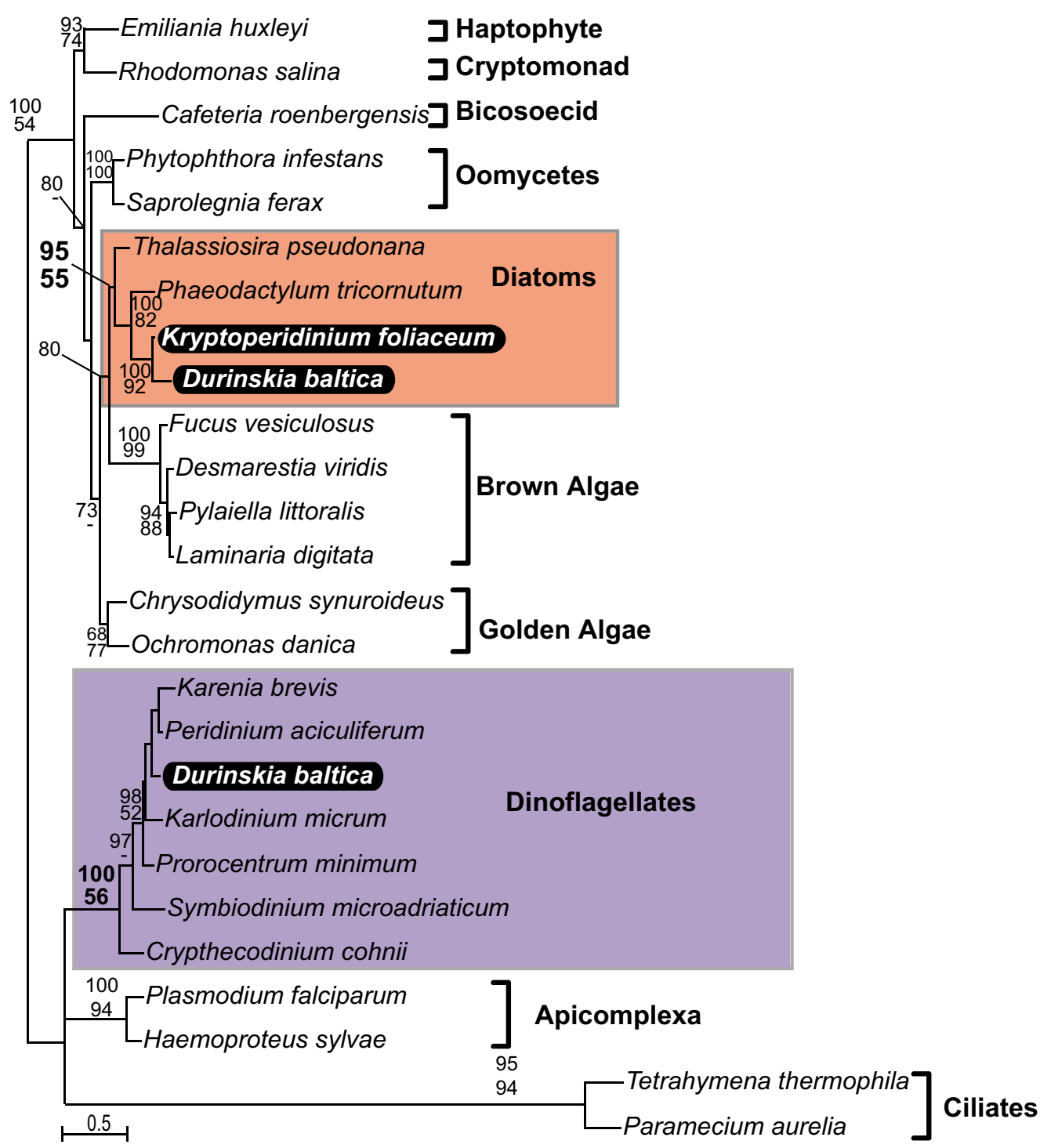

\section{Figure 4}

Protein maximum likelihood phylogeny of cytochrome b (cob). Numbers at nodes indicate bootstrap support for major nodes over 50\% from ML (top) and distance (bottom). A dash (-) indicates support less than $50 \%$. Major groups are labeled to the right, with diatoms (red) and dinoflagellates (purple) indicated by a box and D. baltica and K. foliaceum genes in black.

the point of insertion. One pair of DNA and cDNA clones (Fig. 6, DNA1 and RNA3) were found to be identical, with the exception of edited sites (see below).

A single transcript of the K. foliaceum cox1 was also recovered from sequencing 15 identical clones. This transcript also contained an insert, but without sequence similarity to anything known and not at a position in common with any D. baltica clone. We failed to identify $c o b$, but considering its presence in D. baltica we feel it is unlikely to be absent in $K$. foliaceum.
The many variants of the D. baltica host $\operatorname{cox} 1$ gene and the insert in the K. foliaceum cox 1 gene are both consistent with the nature of mitochondrial genomes in other dinoflagellates. This has been best described in Crypthecodinium cohni and Amphidinium carterae, where protein-coding genes are flanked by non-coding, repeat-rich sequences and that the context of a gene can vary in different copies due to homologous recombination $[21,39]$, and in Oxyrrhis marina where protein coding genes are found in different genomic contexts, and are often fragmented [23]. 


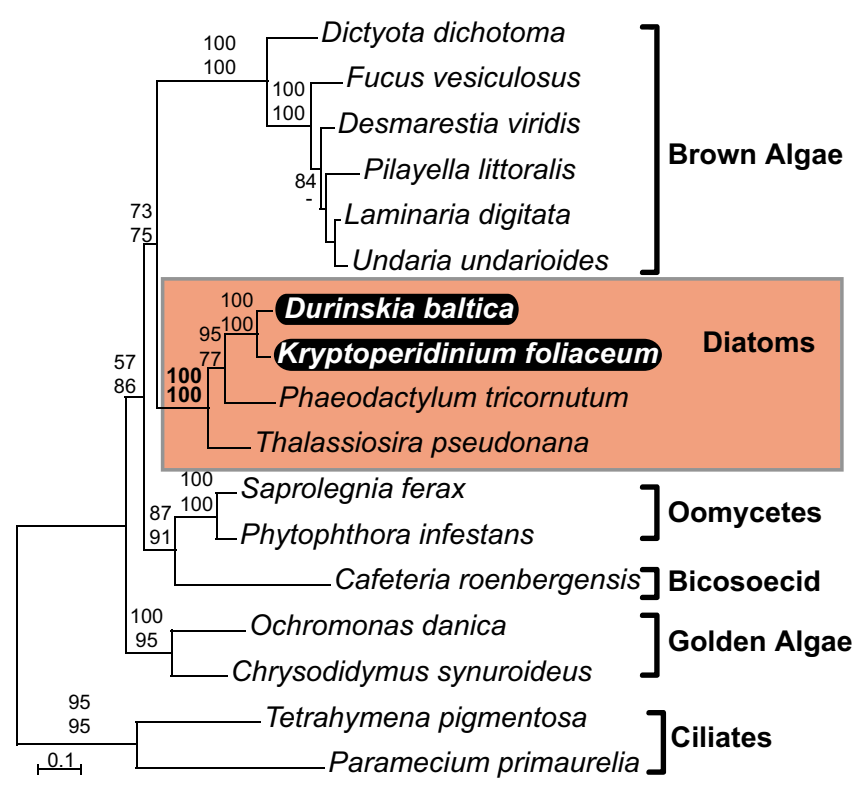

Figure 5

Maximum likelihood phylogeny of large subunit ribosomal RNA (LSUrRNA) under General TimeReversible (GTR) model of substitution. Numbers at nodes indicate bootstrap support for major nodes over $50 \%$ from ML (top) and distance (bottom). A dash (-) indicates support less than $50 \%$. Major groups are labeled to the right, with diatoms (red) indicated by a box and $D$. baltica and $K$. foliaceum genes in black.

\section{Host mitochondrial transcripts are extensively edited}

Dinoflagellate mitochondria possess a distinctive form of RNA editing. Editing sites typically involve A to $\mathrm{G}, \mathrm{T}$ to $\mathrm{C}$, and $\mathrm{C}$ to $\mathrm{U}$ changes at first and second positions, affecting about $2 \%$ of positions in $\operatorname{cox} 1$ and $c o b$ genes $[22,35,40]$. The presence of such editing would provide further evidence for the dinoflagellate mitochondrial location of the cox 1 and $c o b$ genes identified here, so all $D$. baltica gene fragments were aligned to their respective transcripts and conserved editing sites examined. In total, 786 bp of cox 1 were comparable, and 352 bp of cob were comparable, from which 11 and 7 edited sites were identified, respectively. The nature of these edits was similar to that of other dinoflagellates (Table 1) and, significantly, all but three of the editing sites were conserved in other dinoflagellate mitochondria $[22,35,40]$. Overall, the characteristics of this editing are consistent with these genes and cDNAs being located in the dinoflagellate host mitochondria.

\section{Reduction and functional redundancy of mitochondria}

Electron microscopy has shown that mitocondria exist in both the host and endosymbiont cytosolic compartments of $D$. baltica and $K$. foliaceum $[11,12,16]$. More recently diatom-derived genes for $\operatorname{cox} 1, \operatorname{cox} 3$, and $\operatorname{cob}$ have been shown to be expressed in K. foliaceum [9]. However, without comparable data from the host mitochondria it is impossible to determine whether the two organelles are functionally redundant, or have distributed functions between them. Here, we have shown that both organelles contain at least two genes with central functions in electron transport, cox 1 and cob. Accordingly, these two spe-
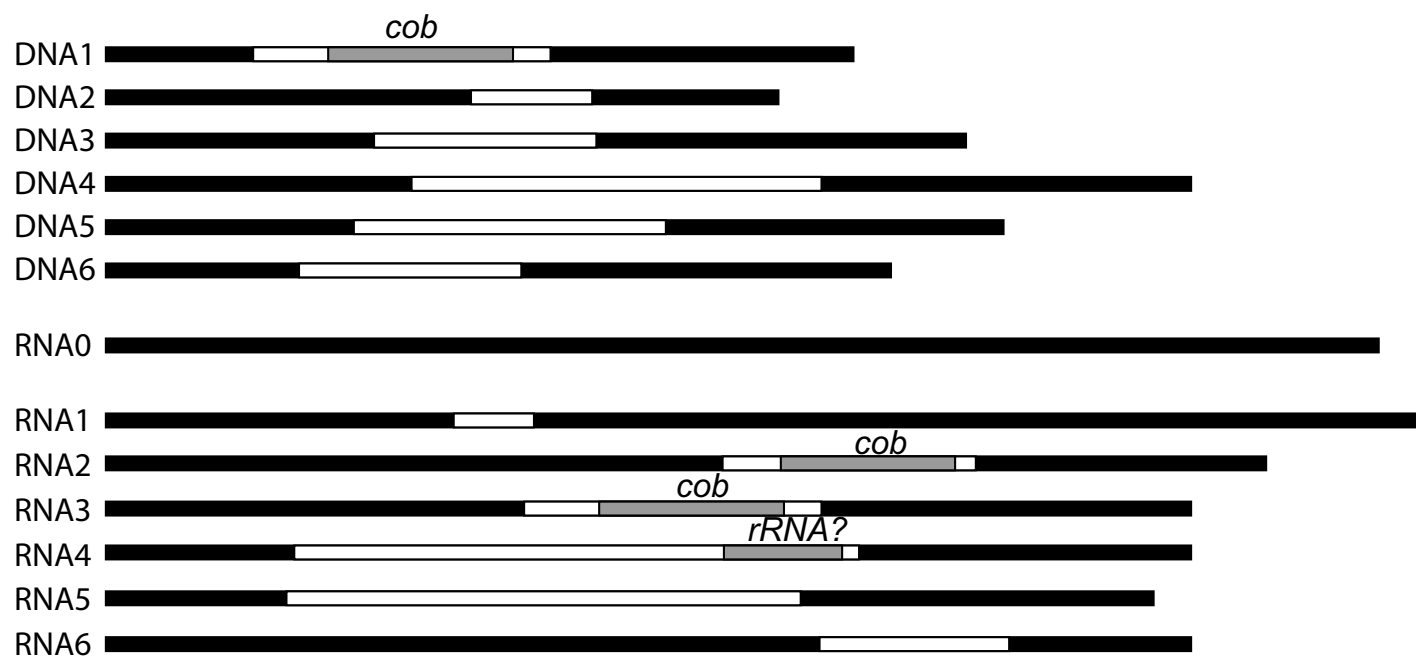

Figure 6

Schematic representation of coxl gene and cDNA fragments characterised from Durinskia baltica. The black rectangles represent coding regions of the gene or the transcript. The white rectangles represent the inserts. The inserts that contain a fragment of another gene have been represented by gray rectangles. The scale is proportional to the number of nucleotides. 
Table I: Editing sites in the host mitochondrial mRNA of coxI and cob in Durinskia baltica

\begin{tabular}{|c|c|c|c|c|c|}
\hline Site Relative to $C_{c}$ or $P p$ & DNA & RNA & Codon Position & Change aa & Conserved in \\
\hline $\operatorname{cox} 1330$ & A & G & Ist & $\mathrm{I}-\mathrm{V}$ & $P p$ and $C_{c}$ \\
\hline $\operatorname{cox} \mid 351$ & $\mathrm{~T}$ & C & Ist & $F-L$ & $P p$ and $C_{c}$ \\
\hline $\operatorname{cox} 1469$ & $\mathrm{C}$ & $U$ & 2nd & $T-1$ & Uniquel \\
\hline $\operatorname{cox} \mid 481$ & $\mathrm{C}$ & $\cup$ & 2nd & $S-F$ & $P p$ and $C_{c}$ \\
\hline coxl 495 & $\mathrm{~T}$ & C & Ist & $F-L$ & $P p$ and $C_{c}$ \\
\hline $\operatorname{cox} \mid 621$ & $A$ & G & Ist & $\mathrm{I}-\mathrm{V}$ & $P p$ and $C_{c}$ \\
\hline $\operatorname{cox} 1691$ & A & G & 2nd & $Y-C$ & $P p$ \\
\hline $\operatorname{cox} 1924$ & $A$ & G & Ist & $\mathrm{I}-\mathrm{V}$ & $P p$ and $C_{c}$ \\
\hline $\operatorname{cox} / 952$ & $\mathrm{~T}$ & $\mathrm{C}$ & 2nd & $L-S$ & $P p$ and $C_{c}$ \\
\hline $\operatorname{cox} 11174$ & $A$ & G & 2nd & $\mathrm{K}-\mathrm{R}$ & $P p$ and $C_{c}$ \\
\hline $\operatorname{cox} I 1180$ & $A$ & G & 2nd & $N-S$ & $P p$ and $C_{c}$ \\
\hline $\operatorname{cob} 782$ & $\mathrm{~T}$ & $\mathrm{C}$ & 2nd & $V-A$ & Pp, Cc, Pmic, Km, Pmin, Ps, At \\
\hline cob 788 & G & $\mathrm{C}$ & 2nd & $G-A$ & Pp, Pmic, Km, Pmin, Ps, At \\
\hline $\operatorname{cob} 861$ & $\mathrm{C}$ & $U$ & $3 r d$ & Silent & Pmic, Pmin, $K m$ \\
\hline $\operatorname{cob} 883$ & A & G & Ist & $\mathrm{I}-\mathrm{V}$ & Pmic, Pmin, K.m. \\
\hline cob 904 & A & G & Ist & $\mathrm{T}-\mathrm{A}$ & Pmic and Pmin \\
\hline cob 1064 & G & $\mathrm{C}$ & 2nd & $G-A$ & Unique $^{2}$ \\
\hline $\operatorname{cob} 1081$ & C & $U$ & Ist & $\mathrm{H}-\mathrm{V}$ & Unique $^{2}$ \\
\hline
\end{tabular}

Column I is the site numbered according to genes from Crypthecodinium cohnii (coxl) or Pfiesteria piscicida (cob). Column 2 and 3 are pre-edited and post-edited states in D. baltica. Column 4 is the position within the codon. Column 5 is the amino acid change. Column 6 lists other dinoflagellates where the same editing is found. Abbreviations: Pp, Pfiesteria piscicida; Cc, Crypthecodinium cohnii; Pmic, Prorocentrum micans; Prorocentrum minimum; Km, Karlodinium micrum; Ps, Pfiesteria shumwyae; At, Alexandrium tamarense.

I This change is absent in $P p$ and $C_{c}$.

2 These changes are absent in $P p$ and not sampled from $C c$.

cies are unique among eukaryotes in having retained active, functional mitochondrial genomes from two distantly related eukaryotic lineages, the dinoflagellate host and the pennate diatom endosymbiont. Moreover, these organelles now appear to be at least partially functionally redundant, since both express genes for proteins in the electron transport chain.

Indeed, no characteristic of either host or endosymbiont mitochondrial genes or genomes has so far been shown to be significantly different from those of their dinoflagellate or diatom relatives, which points to the conclusion that neither organelle has been much affected by the presence of the other. It seems unlikely that the two mitochondria are retained due to functional differentiation, but their genetic redundancy may be related to spatial differentiation. If the membrane separating the host and the endosymbiont, which is thought to be derived from the diatom plasma membrane [20], were deficient in transporters to efficiently shuttle either substrates or products of mitochondrial reactions between the two compartments, then neither compartment could eliminate those functions without consequences. In other endosymbiotic events such difficulties would have been overcome or made irrelevant by the continued reduction of the endosymbiont and integration with the host. Whether the mitochondrion of $D$. baltica is a snapshot in the progression of events that will ultimately lead to its loss, or whether the process has been 'stuck' in some way is unknown. Simi- larly, although it is generally assumed that the endosymbiont will be reduced and the corresponding host feature retained, this does not need to be the case. With the already highly reduced and unusual nature of dinoflagellate mitochondrial genome $[21,23,39]$, it is not unreasonable to hypothesize that the host organelle may be lost as easily as the relatively normal mitochondrion of the endosymbiont.

\section{Conclusion}

We have shown that two related dinoflagellates, $D$. baltica and $K$. foliaceum, retain redundant genes in their hostderived and endosymbiont-derived mitochondrial genomes, including several genes related to electron transport. Host-derived genes are edited at the RNA level and subject to extensive recombination, as is expected for dinoflagellate mitochondria. All genes characterized have been shown to be expressed at the mRNA level, suggesting the two organelles overlap in function, making these unique among eukaryotes in retaining two partially redundant mitochondria with different evolutionary origins.

\section{Methods}

\section{Culture conditions and nucleic acid extraction}

Cultures of Durinskia baltica (Peridinium balticum) CS-38 were obtained from CSIRO Microalgae Supply Service (CSIRO Marine and Atmospheric Research Laboratories, Tasmania, Australia) and maintained in GSe medium at 
$22^{\circ} \mathrm{C}(12: 12$ light : dark cycle). Cultures of Kryptoperidinium foliaceum CCMP 1326 were obtained from the Provasoli-Guillard National Center for Culture of Marine Phytoplankton (West Boothbay Harbor, ME, USA) and maintained in F/2-Si medium under the above-mentioned conditions. Cultures were grown both with and without antibiotics to reduce the number of bacteria: 500 $\mu \mathrm{g} / \mathrm{ml}$ penicillin $\mathrm{G}, 200 \mu \mathrm{g} / \mathrm{ml}$ ampicillin, $50 \mu \mathrm{g} / \mathrm{ml}$ streptomycin sulphate, and $50 \mu \mathrm{g} / \mathrm{ml}$ neomycin, modified from [19]. Cultures used in some molecular experiments did not contain antibiotics, while others did. Exponentially growing cells were harvested by centrifugation at $3,220 \mathrm{~g}$ for $5 \mathrm{~min}$ at $8^{\circ} \mathrm{C}$, and the pellet was frozen and ground under liquid nitrogen. The total genomic DNA was extracted from about $100 \mathrm{mg}$ of the ground cells using DNeasy Plant DNA isolation kit (Qiagen, Mississauga, ON). Total RNA was isolated using TRIzol Reagent (Invitrogen, Burlington, ON) from the pelleted cells following manufacturer's instructions, and it was treated with Deoxyribonuclease I (Invitrogen). PCR was carried out using PuReTaq (Amersham Biosciences, Baie d'Urfé, QC) and long range PCR using Elongase Enzyme Mix (Invitrogen). RT-PCR was carried out using SuperScript III One-Step System with Platinum Taq DNA Polymerase (Invitrogen).

\section{Amplification and sequencing of mitochondrial genes and cDNAs}

From genomic DNA of D. baltica, for amplification of the endosymbiont genes we used the following primers: for LSURRNA gene, 5'-TTCTGCGAAATCTATTKAAGTAGAGCG-3' and 5'-CYGGCGTACCTTTTATCCRTTGMGC3'; for $c o b$ gene, 5'-CCCTTACAGCAATTCCATTCGGAGGTCAAA-3' and 5'-TTCGCCCTTCTGGAATACAATTATCAGGAT-3'; for cox3 gene, 5'TTACAGGTGGTGTTCTTTATATGCACAAAA-3' and 5'AGCCGAAGTGGTGGGGTATTTGTTGAGTGGT-3'; for cox2 gene, first we used the following two degenerate primers, 5'-ATCGGGCATCAGTGGTAYTGGWSNTAYGA3' and 5'-GTTTATCCCGCAGATYTCNSWRCAYTGNCC-3' and later the following specific primers, 5'-GTATTGGAGGTACGAGATTTCGGACTTTGA-3' and 5'-CGGAGCACTGACCAAAGAACATACCCACA-3'; for $\operatorname{cox} 1$ gene, 5'GTTGTTACCCACCTTCTCTTTTACTACTGAT-3' and 5'GCAACAACGTAATAAGTATCGTGAGGAGCA-3'. For amplification of the host genes in $D$. baltica from genomic DNA, and all the cox 1 products containing an insert, we used the following primers: for $\operatorname{cox} 1$, first we used the following two primers previously described [35], 5'AAAAATTGTAATCATAAACGCTTAGG-3' and 5'-TGTTGAGCCACCTATAGTAAACATTA-3', and later the following two specific primers, 5'GCACTTCTTTCATGAGTTTATCACCTTCAAG-3' and 5'TTCTGAGCTGTAACAATGGCGGATTCCCA-3'; for $c o b$, initially the following two primers were used, 5'-GGGGTGCTACGGTTATTACGAACCTACTA-3' and 5'-
TGCCTAACAAAAATGCAGGATTCATAGTCT-3', and later the following primer was used to amplify the 3 ' end of the gene in 3' RACE using RLM-RACE kit (Ambion, Austin, TX, USA) following the manufacturer's instructions, 5'GCATTAGAAGCTTGTGCATTACTTACTCCT-3'. From genomic DNA of $K$. foliaceum, for amplification of the endosymbiont genes we used the following primers: for LSUrRNA gene, 5'-AACAGACAGTCCATGAGTGCTAAGATTCAT-3', and 5'-CACACAGAATTACCGGATCACTATAACCGA-3'; for $\operatorname{cox} 2$ gene, we first used the following two degenerate primers, 5'-GGGCATCAGTGGTATTGGWSNTAYGARWW-3' and 5'-GTTTATCCCGCAGATYTCNSWRCAYTGNCC-3', and later the following two specific primers, 5'-GGGCATCAGTGGTATTGGTGGTACGAAAT-3' and 5'-GTTTATCCCGCAGATTTCGCTGCACTGGCC-3'. For amplification of the host $\operatorname{cox} 1$ in $K$. foliaceum from total RNA, we used the two previously described primers [35], 5'-AAAAATTGTAATCATAAACGCTTAGG-3' and 5'-TGTTGAGCCACCTATAGTAAACATTA-3', using RT-PCR. Transcripts of all the genes were characterized by RT-PCR using the same primers, and all these amplifications were carried out with controls lacking RT enzyme, from which no products were acquired.

We also used three pairs of dinoflagellate-specific primers to search for the host $c o b$ in K. foliaceum, which were based on the most conserved regions of this gene found in dinoflagellate mitochondria. Two pairs of these primers were tested successfully to amplify this gene from $D$. baltica (data not shown). However, no product was obtained with any of these primers from the total DNA or RNA extracted from K. foliaceum used in PCR and RT-PCR respectively.

All PCR and RT-PCR products were gel purified and cloned using pCR 2.1 TOPO Cloning kit (Invitrogen). In each case, several clones were sequenced on both strands using BigDye terminator chemistry. New sequences have been deposited into GenBank as accessions EF434607EF434629.

\section{Phylogenetic analyses}

The conceptual translations of new $\operatorname{cox} 1, \operatorname{cox} 2, \operatorname{cox} 3$, and $c o b$, and DNA sequences for LSUrRNA from D. baltica and $K$. foliaceum were aligned with homologues from public database using ClustalX 1.83.1 [41] under the default gap opening and gap extension penalties and the alignments edited manually. Phaeodactylum tricornutum homologues were kindly provided by Marie-Pierre Oudot-Le Secq from the P. tricornutum genome sequencing project [42]. Phylogenetic analyses were carried out including a diversity of eukaryotes to determine the overall position of new sequences, and subsequently restricted to homologues from chromalveolate taxa (dinoflagellates, apicomplex- 
ans, ciliates, heterokonts, haptophytes, and cryptomonads), since both the host and endosymbiont are thought to be members of this supergroup [43]. No LSUrRNA sequences for dinoflagellates or apicomplexans were included since these genes are fragmented, only partially described to date, and highly divergent, so ciliates alone represent alveolates. These alignments consisted of 52,20, 20, and 26 amino acid sequences, and 17 DNA sequences with 378, 109, 251, 372, and 1304 unambiguously aligned sites for cox1, cox2, cox3, cob, and LSUrRNA, respectively. For cox 1 and $c o b$ sequences, several alignment alternatives were attempted, which were independently followed by phylogenetic analyses. These alternative alignments differed only in the inclusion or exclusion of missing sites. In order to make use of all the recovered sequence data, the alignments of $\operatorname{cox} 1$ and $\operatorname{cob}$ that were analysed included some missing data and either the 5 ' or 3 ' ends of certain D. baltica or K. foliaceum genes. Phylogenies of $\operatorname{cox} 1$ and $c o b$ were also performed using excluding either host or endosymbiont genes, resulting in no significant differences (not shown). All alignments are available upon request.

Phylogenetic trees were inferred using maximum likelihood and distance methods. The proportion of invariable sites (i) and shape parameter alpha $(\alpha)$ with 8 variable rate categories were estimated from the data with PhyML 2.4.4 [44] under the Whelan and Goldman (WAG) model of substitution for $\operatorname{cox} 1, \operatorname{cox} 2, \operatorname{cox} 3$, and $\operatorname{cob}$ phylogenies, and under General Time-Reversible (GTR) model of substitution for LSUrRNA phylogeny with the frequency of amino acid or nucleotide usage calculated from the data. The $\mathrm{i}$ and $\alpha$ parameters estimated from the data were $0.000,0.057,0.004,0.010$, and 0.113, and 1.002, 1.297, $1.186,1.402$ and 1.002 for $\operatorname{cox} 1, \operatorname{cox} 2, \operatorname{cox} 3, \operatorname{cob}$, and LSUr$R N A$, respectively. For all five data sets 1,000 bootstrap replicates were analyzed using PhyML. For distance trees, distances were calculated using TREE-PUZZLE 5.2 [45] with 8 variable rate categories and invariable sites. The $\mathrm{i}$ and $\alpha$ parameters were estimated by TREE-PUZZLE to be $0.00,0.05,0.00,0.00$, and 0.10, and 0.94, 1.18, 1.03, 1.12 , and 0.91 for $\operatorname{cox} 1, \operatorname{cox} 2, \operatorname{cox} 3, \operatorname{cob}$, and LSUrRNA, respectively. Trees were constructed by weighted neighbor-joining using WEIGHBOR 1.0.1a [46]. Distance bootstrapping of 1,000 replicates was carried out using PUZZLEBOOT (shell script by A. Roger and M. Holder).

\section{Competing interests}

The author(s) declares that there are no competing interests.

\section{Authors' contributions}

BI characterized new molecular sequences, carried out phylogenetic analysis and drafted the manuscript. PJK conceived of the study, participated in its design, partici- pated in sequence analysis, and helped draft the manuscript. Both BI and PJK read and approved the final manuscript.

\section{Acknowledgements}

This work was supported by a grant from the Natural Sciences and Engineering Research Council of Canada to PJK. We would like to thank MariePierre Oudot-Le Secq and Chris Bowler for providing mitochondrial sequences from $P$. tricornutum prior to publication, Ross Waller for sharing cox2 alignment, and Allen Larocque for technical assistance. PJK is a Fellow of the Canadian Institute for Advanced Research and a Senior Investigator of the Michael Smith Foundation for Medical Research.

\section{References}

I. Gray MW, Burger G, Lang BF: Mitochondrial evolution. Science 1999, 283:|476-|48I.

2. Palmer JD: The symbiotic birth and spread of plastids: How many times and whodunit? J Phycol 2003, 39:4-I I.

3. Bui ETN, Bradley PJ, Johnson PJ: A common evolutionary origin for mitochondria and hydrogenosomes. Proc Natl Acad Sci USA 1996, 93:965I-9656.

4. Roger AJ: Reconstructing early events in eukaryotic evolution. Am Nat 1999, 154:SI46-SI63.

5. Williams BAP, Keeling PJ: Cryptic organelles in parasitic protists and fungi. Adv Parasitol 2003, 54:9-68.

6. Archibald JM, Keeling PJ: Recycled plastids: A 'green movement' in eukaryotic evolution. Trends Genet 2002, 18:577-584.

7. Tachezy J, Sanchez LB, Muller M: Mitochondrial type iron-sulfur cluster assembly in the amitochondriate eukaryotes Trichomonas vaginalis and Giardia intestinalis, as indicated by the phylogeny of IscS. Mol Biol Evol 200I, 18:1919-1928.

8. van der Giezen M, Tovar J: Degenerate mitochondria. EMBO Rep 2005, 6:525-530.

9. Imanian B, Carpenter K J., Keeling PJ: The mitochondrial genome of a tertiary endosymbiont retains genes for electron transport proteins. J Eukaryot Microbiol 2007, 54: I46-I53.

10. Carty S, Cox ER: Kansodinium new-genus and durinskia newgenus two genera of freshwater dinoflagellates pyrrophyta. Phycologia 1986, 25: 197-204.

II. Dodge JD: A dinoflagellate with both a mesokaryotic and a eukaryotic nucleus: Part I fine structure of the nuclei. Protoplasma 197I, 73:145-157.

12. Jeffrey SW, Vesk M: Further evidence for a membrane bound endosymbiont within the dinoflagellate Peridinium foliaceum. J Phycol 1976, 12:450-455.

13. Tamura M, Shimada S, Horiguchi T: Galeidinium rugatum gen. et sp. nov. (Dinophyceae), a new coccoid dinoflagellate with a diatom endosymbiont. J Phycol 2005, 4I:658-67I.

14. Inagaki Y, Dacks JB, Doolittle WF, Watanabe KI, Ohama T: Evolutionary relationship between dinoflagellates bearing obligate diatom endosymbionts: Insight into tertiary endosymbiosis. Int J System Evol Microbiol 2000, 50:2075-208I.

15. Horiguchi T, Takano Y: Serial replacement of a diatom endosymbiont in the marine dinoflagellate Peridinium quinquecorne (Peridinales, Dinophyceae). Phycological Res 2006, 54:193-200.

16. Tomas RW, Cox ER: Observations on the symbiosis of Peridinium balticum and its intracellular alga. J Phycol 1973, 9:304-323.

17. Chesnick J, Cox ER: Fertilization and zygote development in the binucleate dinoflagellate Peridinium balticum (Pyrrhophyta). Am J Bot 1989, 76:1060-1072.

18. Tippit DH, Pickett-Heaps JD: Apparent amitosis in the binucleate dinoflagellate Peridinium balticum. J Cell Sci 1976, 21:273-289.

19. Kite GC, Rothschild LJ, Dodge JD: Nuclear and plastid DNAs from the binucleate dinoflagellates Glenodinium foliaceum and Peridinium balticum. Biosystems 1988, 21:151-164.

20. Eschbach $S$, Speth $V$, Hansmann P, Sitte P: Freeze-fracture study of the single membrane between host cell and endocytobiont in the dinoflagellates Glenodinium foliaceum and Peridinium balticum. JPhycol 1990, 26:324-328. 
21. Norman JE, Gray MW: A complex organization of the gene encoding cytochrome oxidase subunit $I$ in the mitochondrial genome of the dinoflagellate Crypthecodinium cohnii: humologous recombination generates two different coxI open reading frames. J Mol Evol 200I, 53:35I-363.

22. Zhang $\mathrm{H}$, Lin S: Mitochondrial cytochrome $b$ mRNA editing in dinoflagellates: Possible ecological and evolutionary associations? Journal of Eukaryotic Microbiology 2005, 52:538-545.

23. Slamovits $\mathrm{CH}$, Saldarriaga JF, Larocque A, Keeling PJ: The highly reduced and fragmented mitochondrial genome of the earlybranching dinoflagellate Oxyrrhis marina shares characteristics with both apicomplexan and dinoflagellate mitochondrial genomes. J Mol Biol 2007, 372:356-268.

24. Fast NM, Xue L, Bingham S, Keeling PJ: Re-examining alveolate evolution using multiple protein molecular phylogenies. J Eukaryot Microbiol 2002, 49:30-37.

25. Van de Peer $Y$, De Wachter R: Evolutionary relationship among the eukaryotic crown taxa taking into account site-to-site rate variation in I8S rRNA. J Mol Evol 1997, 45:615-630.

26. Rice DW, Palmer JD: An exceptional horizontal gene transfer in plastids: gene replacement by a distant bacterial paralog and evidence that haptophyte and cryptophyte plastids are sisters. BMC Biol 2006, 4:31.

27. Harper JT, Waanders E, Keeling PJ: On the monophyly of chromalveolates using a six-protein phylogeny of eukaryotes. Int J System Evol Microbiol 2005, 55:487-496.

28. Patron NJ, Inagaki Y, Keeling PJ: Multiple gene phylogenies support the monophyly of cryptomonad and haptophyte host lineages. Curr Biol 2007, 1 7:887-89I.

29. Hackett JD, Yoon HS, Li S, Reyes-Prieto A, Rummele SE, Bhattacharya $D$ : Phylogenomic analysis supports the monophyly of cryptophytes and haptophytes and the association of 'Rhizaria' with chromalveolates. Mol Biol Evol 2007, 24: I702-17।3.

30. Morris RL, Fuller CB, Rizzo PJ: Nuclear basic proteins from the binucleate dinoflagellate Peridinium foliaceum (Pyrrophyta). J Phycol 1993, 29:342-347.

31. Horiguchi T, Pienaar RN: Ultrastructure of a new marine sanddwelling dinoflagellate, Gymnodinium quadrilobatum sp. nov. (Dinophyceae) with special reference to its endosymbiotic alga. Europ J Phycol 1994, 29:237-245.

32. Horiguchi T, Pienaar RN: Ultrastructure of a marine dinoflagellate, Peridinium quinquecorne Abe (Peridiniales) from South Africa with special reference to its chrysophyte endosymbiont. Botanica Marina 1991, 34:123-131.

33. Chesnick JM, Kooistra WHC, Wellbrock U, Medlin LK: Ribosomal RNA analysis indicates a benthic pennate diatom ancestry for the endosymbionts of the dinoflagellates Peridinium foliaceum and Peridinium balticum (Pyrrophyta). J Eukaryot Microbiol 1997, 44:3|4-320.

34. McEwan M, Keeling PJ: HSP90, tubulin and actin are retained in the tertiary endosymbiont genome of Kryptoperidinium foliaceum. J Eukaryot Microbiol 2004, 5 I:65 I-659.

35. Lin S, Zhang H, Spencer DF, Norman JE, Gray MW: Widespread and extensive editing of mitochondrial mRNAS in dinoflagellates. J Mol Biol 2002, 320:727-739.

36. Zhang $\mathrm{H}$, Lin S: Mitochondrial cytochrome b mRNA editing in dinoflagellates: possible ecological and evolutionary associations? J Eukaryot Microbiol 2005, 52:538-545.

37. Gray MW: Diversity and evolution of mitochondrial RNA editing systems. IUBMB Life 2003, 55:227-233.

38. Kamikawa R, Inagaki Y, Sako Y: Fragmentation of mitochondrial large subunit rRNA in the dinoflagellate Alexandrium catenella and the evolution of rRNA structure in alveolate mitochondria. Protist 2007, 158:239-245

39. Waller RF, Keeling PJ: Alveolate and chlorophycean mitochondrial cox2 genes split twice independently. Gene 2006, 383:33-37.

40. Nash EA, Barbrook AC, Edwards-Stewart RK, Bernhardt K, Howe CJ, Nisbet RE: Organisation of the mitochondrial genome in the dinoflagellate Amphidinium carterae. Mol Biol Evol 2007, 24:1528-1536.

4I. Gray MW, Lang BF, Burger G: Mitochondria of protists. Annu Rev Genet 2004, 38:477-524.

42. Thompson JD, Higgins DG, Gibson TJ: Clustal W: improving the sensitivity of progressive multiple sequence alignment through sequence weighting, position specific gap penalties and weight matrix choice. Nucleic Acids Res 1994, 22:

43. Phaeodactylum tricornutum genome sequencing project [http://www.jgi.doe.gov/index.html]

44. Keeling PJ, Burger G, Durnford DG, Lang BF, Lee RW, Pearlman RE, Roger AJ, Gray MW: The tree of eukaryotes. Trends Ecol Evol 2005, 20:670-676.

45. Guindon S, Gascuel O: A simple, fast and accurate method to estimate large phylogenies by maximum-likelihood. Syst Biol 2003, 53:696-704.

46. Schaefer G, Anemueller S, Moll R: Archaeal complex II: 'Classical' and 'non-classical' succinate:quinone reductases with unusual features. Biochim Biophys Acta 2002, 1553:57-73.

47. Bruno WJ, Socci ND, Halpern AL: Weighted Neighbor Joining: A Likelihood-Based Approach to Distance-Based Phylogeny Reconstruction. Mol Biol Evol 2000, 17:187-197.
Publish with Biomed Central and every scientist can read your work free of charge

"BioMed Central will be the most significant development for disseminating the results of biomedical research in our lifetime. "

Sir Paul Nurse, Cancer Research UK

Your research papers will be:

- available free of charge to the entire biomedical community

- peer reviewed and published immediately upon acceptance

- cited in PubMed and archived on PubMed Central

- yours - you keep the copyright 